\title{
The Use of the Leopold Matrix in Carrying Out the EIA for Wind Farms in Serbia
}

\author{
Bosko Josimovic $^{1}$, Jasna Petric ${ }^{1} \&$ Sasa Milijic $^{1}$ \\ ${ }^{1}$ Centre for Spatial Development and Environment, Institute of Architecture and Urban and Spatial Planning of \\ Serbia, Belgrade, Serbia \\ Correspondence: Bosko Josimovic, Centre for Spatial Development and Environment, Institute of Architecture \\ and Urban and Spatial Planning of Serbia, Belgrade, Serbia. E-mail: bosko@iaus.ac.rs
}

\author{
Received: December 17, 2013 Accepted: December 30, 2013 Online Published: February 24, 2014 \\ doi:10.5539/eer.v4n1p43 \\ URL: http://dx.doi.org/10.5539/eer.v4n1p43
}

\begin{abstract}
Although the Energy Sector Development Strategy of the Republic of Serbia until 2015 envisages an increasing share of renewable energy (RE) in the total energy balance of the country and although there are plenty of wind energy initiatives resulting in the elaboration of planning and project documentation, no wind farms have yet been built in Serbia. One of the significant problems in the realization of these projects is the unjustifiable resistance of a part of local authorities and population, particularly related to the possible environmental impacts of the planned projects. In this context, the paper addresses the possibility of using the Leopold matrix in carrying out the Environmental Impact Assessment (EIA) for "Kladovo" Wind Farm in Serbia (case study). The Leopold matrix is a framework method for assessing the environmental impact of a project. The novelty in this method, presented herein, refers to the evaluation of planned project activities relative to a group of criteria related to: significance (spatial dispersion), probability and duration of impact. The obtained EIA results have enabled the precise identification of possible environmental impacts of "Kladovo" Wind Farm project, as well as removal of dilemmas and problems related to the public resistance to the realization of the project through a transparent relationship with stakeholders.
\end{abstract}

Keywords: Environmental Impact Assessment (EIA), Leopold matrix, wind farm

\section{Introduction}

In 2005, the National Assembly of the Republic of Serbia adopted the Energy Sector Development Strategy of the Republic of Serbia ("Official Gazette of the Republic of Serbia", No. 44/05) defining the elements for determining the energy sector strategy of Serbia. The Strategy also defines the development and use of new sources of renewable energy, as well as the most efficient technologies and devices. According to the abovementioned, the most important goals of Serbian energy policy are harmonized with the EU practice and regulations aiming at increasing energy efficiency and intensifying the use of new sources of renewable energy as a major precondition for achieving the sustainable socio-economic development of the country, as well as for establishing an ecological energy balance. However, little has been done so far in wind energy implementation in Serbia. No wind farms have yet been built, while activities carried out with the aim to build them are still in the stage of the elaboration of the planning/technical documentation and obtaining of building permits (Josimovic \& Pucar, 2010).

Besides the slow state administration, the significant problem in the realization of the wind farms in Serbia is also reflected in the resistance of a part of local authorities and population because of environmental impacts of wind farms. In this context, possible impacts of land-use change and higher intensity noise that may jeopardize the health and welfare or safety of the people who live very close to wind farms are emphasized as the specific problem. In addition, a part of stakeholders express their concern for possible dramatic wind farm impacts on ornithofauna and chiropteran fauna in a wider area.

Analyzing the abovementioned problems and their causes, it has been concluded that carrying out an Environmental Impact Assessment (EIA) presents the key instrument by which it is possible to eliminate these problems, as well as that a special attention within the EIA needs to be paid to:

Avoid rough estimates, predictions and assessments based only on textual comments; 
$>\quad$ The assessment of impacts of the planned project that will be based not only on identification of majority of impacts but also on consideration of different aspects of possible impacts.

In this context, the subject research has focused on further development of one of the current methods used in carrying out an EIA, which has been practiced in Serbia for more than 20 years (Crnčević, Marić, \& Josimović, 2011). Here, it is of particular importance to chose a method which is based on the application of MCDM (Multiple Criteria Decision Making) in the field of environmental protection, because the use of the MCDM enables an analysis of different aspects of project impacts necessary for making decisions which optimize effects of certain activities relative to the capacity of space and environmental capacity. Methods based on the MCDM have a wide application in environmental impact assessment of proposed projects. From the aspect of the environmental impact assessment of wind-energy projects, the ARAS (Additive Ratio Assessment) method is also worth mentioning, which was elaborated in detail by Chatterjee and Bose (2013). From the aspect of quality and applicability, the AHP (Analytical Hierarchy Process) method is of particular importance. It has been widely used after the study of "A new Environmental Performance Index using analytic hierarchy process: A case of ASEAN countries” (Ismail \& Abdullah, 2012).

The Leopold matrix has been chosen as a suitable method. There are several major reasons why precisely this approach to EIA has been chosen as appropriate for further development:

The Leopold matrix presents a framework approach to impact assessment of a project because of which it is possible to creatively work on its further development;

$>\quad$ It is widely applicable in carrying out an EIA for different types of projects. Given that it has been used for many decades now, its major principles are known to scientific and professional circles, thereby implying that the elaboration of the obtained results will be understandable to many scientists and experts;

$>\quad$ The way of presenting the results can be appropriate for overcoming the existing problems in the realization of wind farm projects in Serbia because descriptive and rough assessment of possible impacts is avoided in the practice of carrying out an EIA;

$>\quad$ Leopold matrix fits in the framework MCDM method.

In this paper, we refer to the Leopold matrix as one of the pioneering and widely used approaches to impact assessment, which was the first comprehensive listing of environmental and socio-economic factors. This matrix is two-dimensional, where the stages of almost any type of construction project (actions) are assessed in relation to the existing environmental characteristics and conditions that may be affected during the execution of those actions.

\section{About the Methodology of the Leopold Matrix}

The Leopold matrix was conceived by geologist Luna B. Leopold and his colleagues in 1971, as a response to the US Environmental Policy Act of 1969, which didn't give clear instructions to the Federal Government agencies for preparing an impact report or for examining the environmental effects of the projects that an agency plans. The Leopold matrix addressed this challenge by 'providing a system for the analysis and numerical weighting of probable impacts'. As pointed out by the creators of the Leopold matrix, there is a clear advantage of using the matrix 'as a checklist or reminder' of the large scope of actions and impacts on the environment that can relate to the proposed actions (Leopold, Clarke, Hanshaw, \& Balsley, 1971).

According to the Leopold matrix method, EIA should consist of three basic elements: a) a listing of the effects on the environment that the proposed development may induce, including the estimate of the magnitude of each of the effects (Note 1); b) an evaluation of the importance of each of listed effects (e.g., regional vs. local) (Note 2); and c) a summary evaluation, which is a combination of magnitude and importance estimates.

The format of Leopold matrix evolves around 8,800 possible interactions since the number of actions listed on the horizontal axis in the sample matrix is 100 , and the number of environmental factors listed on the vertical axis of this matrix is 88. As the authors of this method pointed out, there are, however, only a few of the interactions that would deserve comprehensive consideration due to their expressed magnitude and importance, varying between 25 and 50 interactions on average for a typical project (Leopold, Clarke, Hanshaw, \& Balsley, 1971).

In order to achieve higher efficiency of the matrix, a starting point is to check each significant action listed in a horizontal axis. The experience often proves that 'only about a dozen actions will be important' (Leopold, Clarke, Hanshaw, \& Balsley, 1971). Each checked action is evaluated in terms of magnitude of effect on environmental 
factors that are listed in the vertical axis. In the matrix, across each box where significant interaction is expected, a slash (/) is placed diagonally from upper right to lower left angle of the block. In the text which accompanies the Leopold matrix, the evaluator has to indicate whether the assessment is for short-term or long-term impacts. Then, in the upper left-hand angle of each box with a slash, the evaluator should place a number from 1 to 10 , which indicates the magnitude of the possible impact, where 10 represents the greatest magnitude of impact and 1 the least (no zeros should be assigned). The scale of importance (placed in the lower right-hand angle of each box with a slash) may also range from 1 to 10 , with the same principle applied - the higher the value, the higher the importance. Assignment of numerical value for importance is based on subjective judgment of a multi-disciplinary team working in the EIA. In addition to assigning the numerical values to each marked box, plus (+) or minus (-) sign can be used to show whether an impact is beneficial or adverse.

The EIA is a discussion of the individual boxes marked with greater numbers for magnitude and importance. This is commonly applied to a simplified or reduced matrix, which consists only of those actions and environmental characteristics that have been identified as interacting. The rating scheme requires quantification that expresses evaluator's judgment (line of reasoning) in terms of probable impacts. This scheme then enables the reviewer to systematically follow the evaluator's standpoints, to assist in identifying points of agreement and disagreement.

Although most matrices are developed for specific application, Leopold matrix is quite general. That is a plus point for its wider application, as well as the fact that the method can accommodate both quantitative and qualitative data. On the other hand, discrimination between these two types of data is not here provided neither it is possible to explicitly relate the magnitudes of predictions to the 'with action' or 'without action' future states Bhatnagar (2009).

There is an opportunity in the Leopold matrix to double count impacts, therefore the method is not mutually exclusive. One of the strongest points of the Leopold matrix is that it draws a clear line and safeguards evaluator's opinion from the value judgments and political interference by policy makers. This is achieved by disaggregated presentation of detailed assessment results, leaving policy makers with full responsibility for the evaluation synthesis and for drawing its policy implications, and such point has been accepted as an evaluation standard for decades, being also maintained in the EU Impact Assessment Guidelines (SEC(2005)791) (Radej, 2010).

In terms of communication, even though Leopold matrix does not indicate the main issues or the groups of people who are most likely to be affected by the impact, it is still quite effective in communicating the results by providing a visual display on a single diagram (Decree on the Ecological Network, 2010).

\section{CASE STUDY: The Use of Leopold Matrix in Carrying out the EIA for the "Kladovo" Wind Farm, Serbia}

\subsection{Description of Location}

The area where the "Kladovo" Wind Farm is planned is located in the Ključ (Key) region, a large key-like river meander that the Danube forms right after it leaves the Iron Gate Gorge. It is surrounded by the Danube from the north, east and partly from the south, and the M-25 main road (E-771) from the west (Figure 1). The project covers an area of approximately 509 ha.

The location comprises only agricultural land with intensively cultivated monoculture fields, mainly without overgrown boundaries between them. There is a small number of neglected fields, as well as steppes, forest vegetation and wetland habitats.

The "Mala Vrbica" fish pond is located north and east of the immediate surrounding of the location. Because of its rich ornithofauna, the "Mala Vrbica" has a status of internationally and nationally Important Bird Area (IBA), protected by law as an ecologically significant area (Decree on the Ecological Network, 2010). The eastern boundary of the Đerdap National Park is less then $15 \mathrm{~km}$ west from the research area. This area also has the IBA status because of its rich ornithofauna. The area is also characterized by a rich chiropteran fauna. Nevertheless, due to the distance of this protected natural value and the fact that it is separated by the zone of changed urban and agricultural landscapes, the expected impact on the state of ornithofauna in this location is small, while neglectable on the chiropteran fauna.

The monitoring of ornithofauna and chiropteran fauna was carried out in the wider area planned for the "Kladovo" Wind Farm in the period between March 2011 to February 2012. The presence of representatives of 100 bird species was recorded, while the total of 173 bird species were recorded in a wider area of Ključ, including IBA of Mala Vrbica and a part of the Danube river course. Representatives of many of the recorded 
types were present in extremely small number.

The activity of 9 identified species of bats at the location planned for the "Kladovo" Wind Farm was recorded using ultrasound detectors. Despite the considerable number of recorded species, it should be pointed out that, during the monitoring, most of them were recorded in a relatively very small number, i.e. only several times in the total of 4,273 over-flights/contacts. Based on the abovementioned, it can be concluded that, trophically, as well as cryprically, resources for bats in the wind farm location were scarce during the monitoring period.

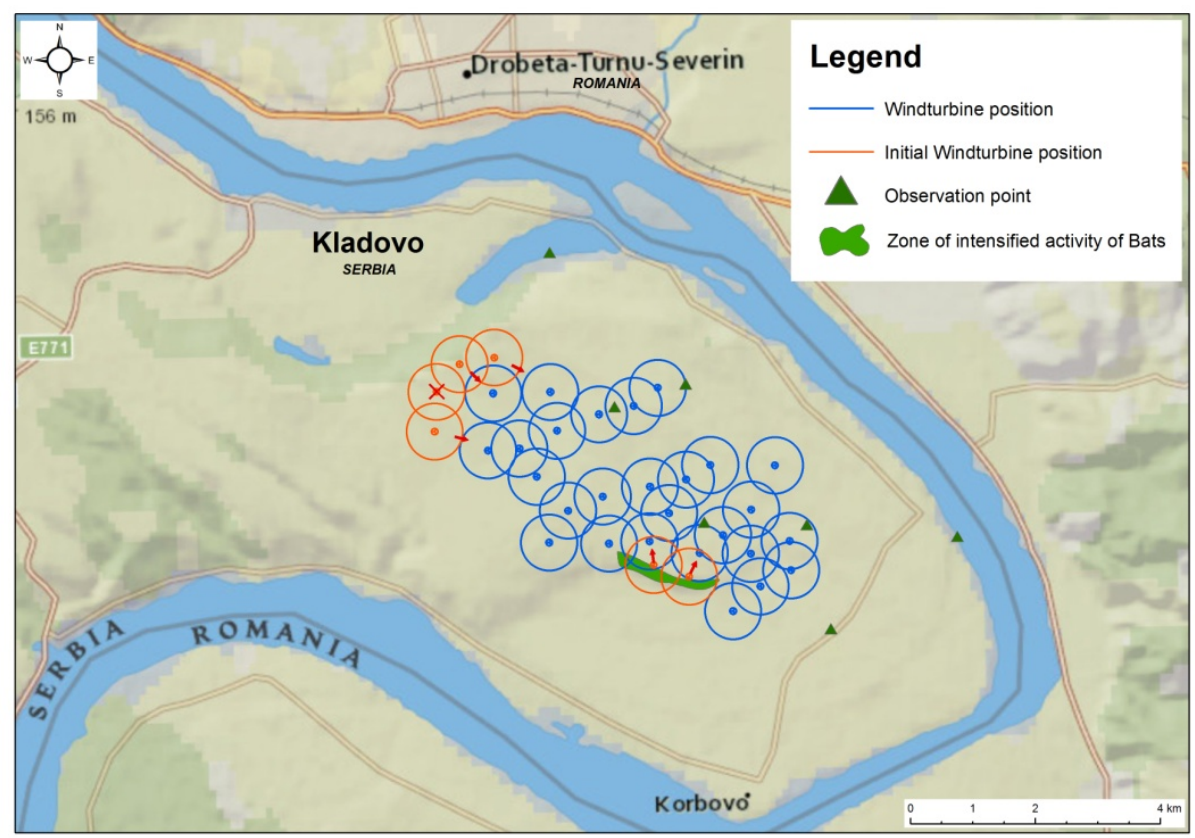

Figure 1. The location for the "Kladovo" Wind Farm relative to its wider surrounding (Source: Google Earth)

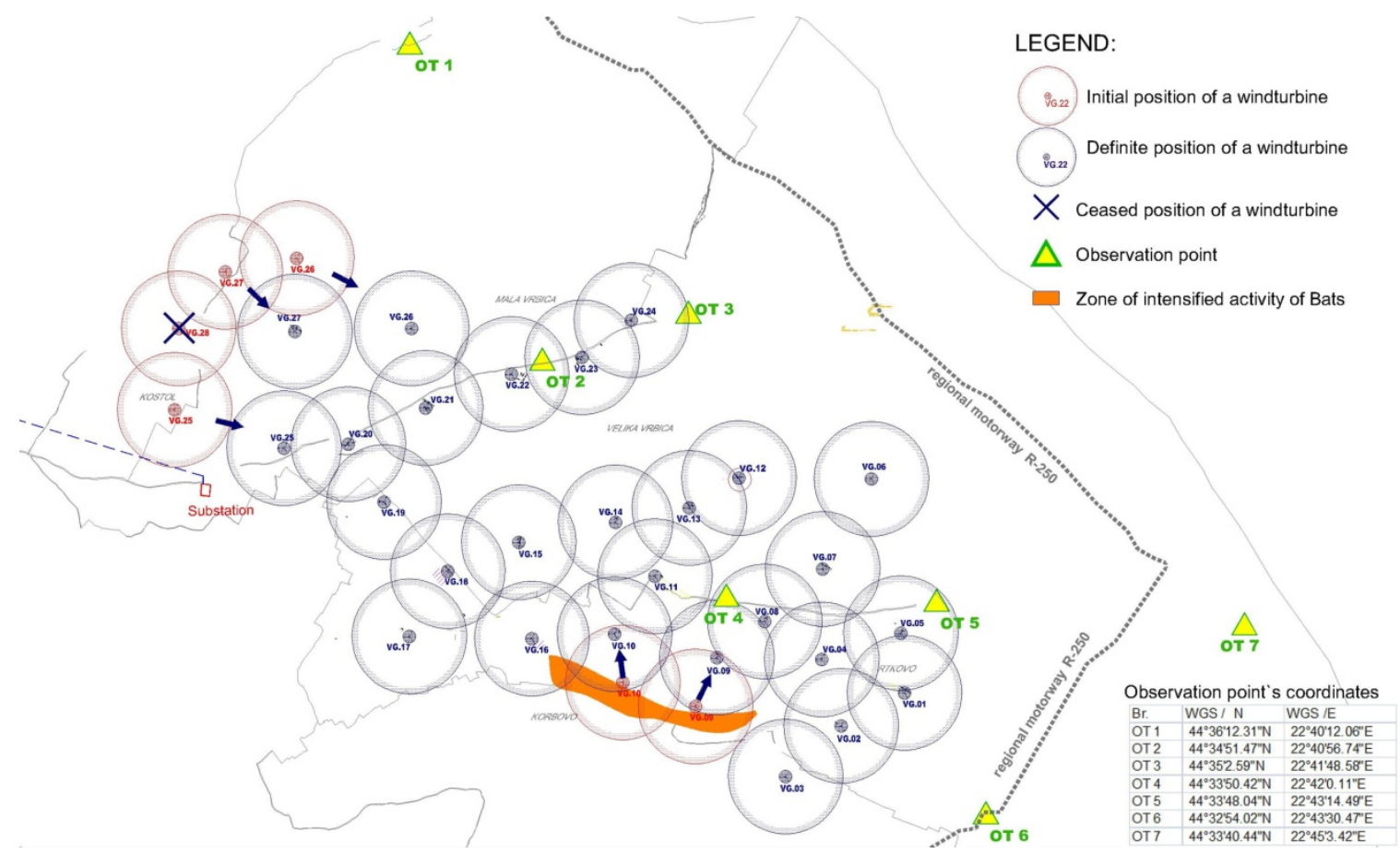

Map 1. Final spatial disposition of wind turbines in the "Kladovo" wind farm adjusted to the results of one year monitoring of ornithofauna and chiropteran fauna 
On Map 1, positions of wind turbine columns, later dislocated in order to protect ornithofauna and chiropteran fauna, are denoted by red color. In addition, one position at the west end of the location has been abandoned as unfavorable relative to possible impacts on certain protected bird species. The project envisages 27 wind turbines of $2 \mathrm{MW}$ each, i.e. the total installed capacity of $54 \mathrm{MW}$.

\subsection{Environmental Impact Assessment Using the Leopold Matrix}

For the analysis of possible impacts of certain activities and procedures during the construction of "Kladovo" Wind Farm and its exploitation on the environmental elements, 9 possible factors, which are actually activities on the realization of the "Kladovo" Wind Farm project, have been singled out from a wider list of potential factors of impacts that can be expected for such type of interventions in nature. Although it is possible to partially determine aggregate, i.e. average assessment of impact factors for each of these components, we consider that it is sufficiently appropriate and functional to present them as a whole. The fact is that some of them are synergistic ones, mutually reinforcing their effects, so that this matching of information should be maintained in the analysis. A synthetic presentation of endangering factors is given through mean values and not through aggregate assessment, which will be later scaled.

Impact factors have been evaluated separately for each environmental component relevant for the scope of this study, and scored on a scale from 0 to 5 for impact magnitude, according to the following scale:

$$
\begin{aligned}
& 0 \text { - no observable effect; } \\
& \text { 1- low effect; } \\
& 2 \text { - tolerable effect; } \\
& 3 \text { - medium high effect; } \\
& \text { 4- high effect; } \\
& 5 \text { - very high effect (devastation). }
\end{aligned}
$$

In addition to the standard form of the Leopold matrix, the following criteria have also been used:

Impact significance with designations from $\mathrm{L}$ to $\mathrm{M}$, according to the following scale:

$\mathrm{L}$ - limited impact on location;

$\mathrm{O}$ - impact of importance for municipality;

$\mathrm{R}$ - impact of regional character;

$\mathrm{N}$ - impact of national character;

$\mathrm{M}$ - impact of cross-border character.

Impact probability with designations from $\mathrm{M}$ to I, according to the following scale:

$$
\begin{aligned}
& \mathrm{M} \text { - impact is possible (probability of less than } 50 \% \text { ); } \\
& \mathrm{V} \text { - impact is probable (probability of over } 50 \% \text { ); } \\
& \mathrm{I} \text { - impact is certain (100\% probability). }
\end{aligned}
$$

Impact duration with designation $\mathrm{P}$ (occasional/temporary) and D (long-term/permanent).

Furthermore, physical, biological and socio-cultural environmental characteristics of the subject location have been separated and, within them, 16 environmental components have been defined.

Effects of impact factors have been assessed for environmental components of the subject location (!). The results of the analysis are shown in Tables 1, 2, 3 and 4 for all environmental components and impact factors in the form of Leopold matrix, and then elaborated in an appropriate way.

\subsection{Elaboration of the Assessed Effects of Impact Factors on Environmental Components}

\subsubsection{Physical Components}

The subject project will not affect groundwater regime and quality. Wind turbines do not consume water, thus there is no waste water. Furthermore, the project will not affect microclimatic characters and parameters, neither will it stimulate the process of erosion.

As for possible impact on land, it can occur primarily as a result of the construction of turbine column foundations, manipulation of construction equipment at the location and inadequate waste material treatment during the wind farm construction. The total average value of expected impact magnitudes is within low effects 
(1.33), dominantly of local character, with permanent or occasional effects.

Certain negative effects of the plan can occur in the phase of wind farm construction as a result of the realization of certain planning concepts, primarily construction of roads for the needs of wind farm complex, as well as wind farm administration complex. These impacts include air pollution caused by construction equipment and vehicles, as well as by created dust. The total average value of magnitudes of expected impacts of construction phase of the subject project on air quality is within low effects (0.77) of local character.

Besides total power capacity and size of wind turbines, the spatial aspect is particularly important when considering the noise intensity. The wind turbine noise decreases with increasing distance from wind turbines. In order to model the noise intensity levels, interpretation of the Regulation on the Methodology for Determining the Acoustic Zone was first interpreted (2010). The complex of the planned wind farm should be considered as the zone VI - industrial zone, while the nearest residential buildings should be considered as zone II - small and rural settlements. The abovementioned conclusion was taken into consideration in assessing the noise intensity levels from and their spatial dispersion in the area covered by the project. The modeling of wind turbine noise levels for the planned wind farm was performed using the Danish "calculator for noise levels from wind turbines" (Figure 2).

Table 1. Matrix of magnitude of the impact of factors on environmental components for WF, "Kladovo"

\begin{tabular}{|c|c|c|c|c|c|c|c|c|c|c|c|c|}
\hline & \multicolumn{12}{|c|}{ PROJECT ACTIVITIES } \\
\hline & 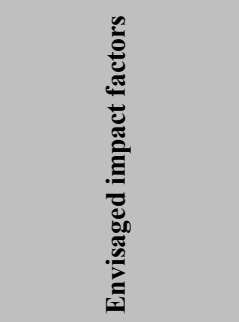 & 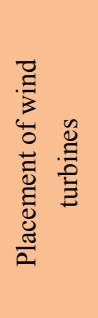 & 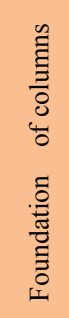 & 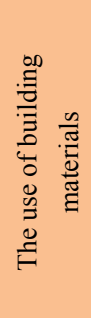 & 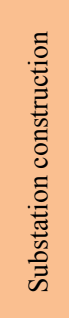 & 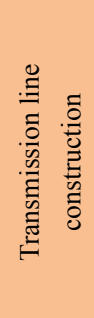 & 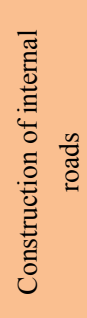 & 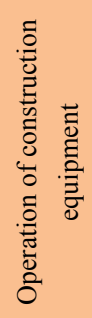 & 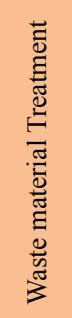 & 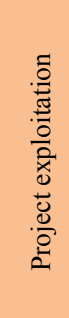 & 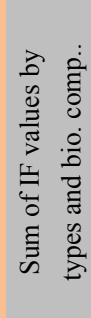 & 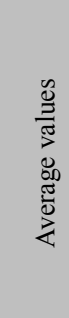 \\
\hline \multirow{6}{*}{$\begin{array}{c}\text { PHYSICAL } \\
\text { COMPONENTS }\end{array}$} & Water & 0 & 0 & 0 & 0 & 0 & 0 & 0 & 0 & 0 & 0 & 0.00 \\
\hline & Microclimate & 0 & 0 & 0 & 0 & 0 & 0 & 0 & 0 & 0 & 0 & 0.00 \\
\hline & Land & 1 & 2 & 1 & 1 & 1 & 1 & 2 & 2 & 1 & 12 & 1.33 \\
\hline & Erosion & 0 & 0 & 0 & 0 & 0 & 0 & 0 & 0 & 0 & 0 & 0.00 \\
\hline & Air & 0 & 0 & 0 & 1 & 0 & 2 & 3 & 1 & 0 & 7 & 0.77 \\
\hline & Noise & 1 & 1 & 1 & 2 & 1 & 2 & 3 & 0 & 2 & 14 & 1.55 \\
\hline \multirow{5}{*}{$\begin{array}{l}\text { BIOLOGICAL } \\
\text { COMPONENTS }\end{array}$} & Diversity of flora & 0 & 1 & 0 & 0 & 1 & 0 & 1 & 1 & 0 & 4 & 0.44 \\
\hline & Diversity of fauna & 2 & 1 & 1 & 1 & 1 & 0 & 2 & 2 & 2 & 12 & 1.33 \\
\hline & Ornithofauna & 2 & 1 & 1 & 1 & 1 & 0 & 2 & 2 & 2 & 12 & 1.33 \\
\hline & Chiropteran fauna & 2 & 1 & 1 & 1 & 1 & 0 & 2 & 2 & 2 & 12 & 1.33 \\
\hline & Barriers/corridors & 2 & 1 & 1 & 1 & 1 & 0 & 1 & 1 & 2 & 10 & 1.11 \\
\hline \multirow{5}{*}{$\begin{array}{l}\text { SOCIO-CULTURAL } \\
\text { COMPONENTS }\end{array}$} & Landscape & 2 & 2 & 1 & 2 & 1 & 1 & 1 & 3 & 2 & 15 & 1.66 \\
\hline & Land use & 1 & 2 & 1 & 1 & 1 & 1 & 1 & 2 & 1 & 11 & 1.22 \\
\hline & Economy & 0 & 0 & 0 & 0 & 0 & 0 & 0 & 0 & 0 & 0 & 0.00 \\
\hline & Cultural heritage & 0 & 2 & 0 & 0 & 0 & 0 & 0 & 0 & 0 & 2 & 0.22 \\
\hline & Accidents & 2 & 0 & 0 & 1 & 0 & 0 & 0 & 2 & 2 & 7 & 0.77 \\
\hline \multicolumn{2}{|c|}{$\begin{array}{l}\text { Cumulative values of IF according to environmental } \\
\text { factors }\end{array}$} & 15 & 14 & 8 & 12 & 9 & 8 & 18 & 18 & 16 & & \\
\hline \multicolumn{2}{|c|}{ Average } & 0.93 & 0.87 & 0.50 & 0.75 & 0.56 & 0.50 & 1.12 & 1.12 & 1.00 & \multicolumn{2}{|c|}{ IF $=0.82$} \\
\hline
\end{tabular}


Table 2. Matrix of significance of the impact of factors on environmental components for WF, "Kladovo"

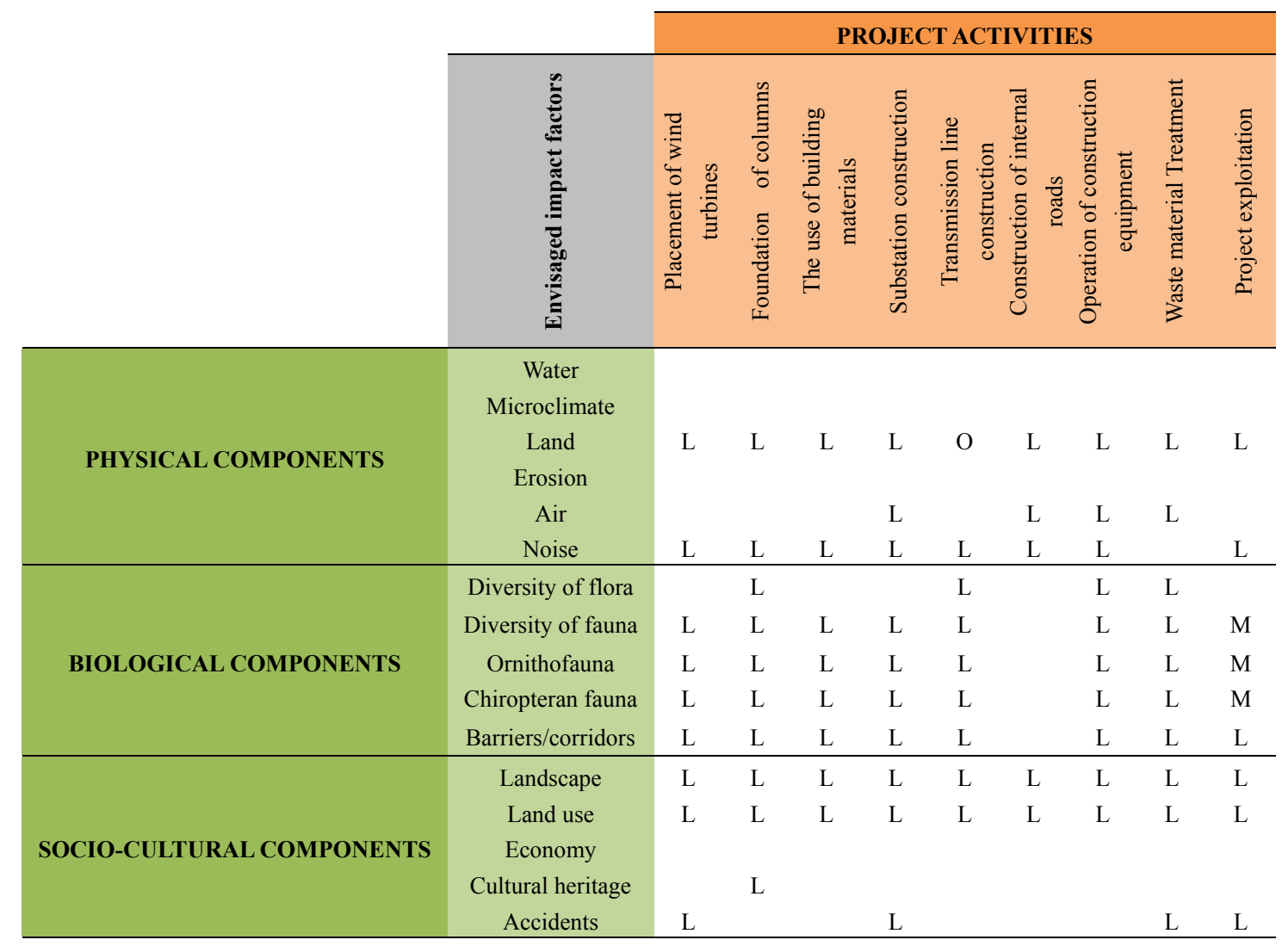

Table 3. Matrix of probability of the impact of factors on environmental components for WF, "Kladovo"

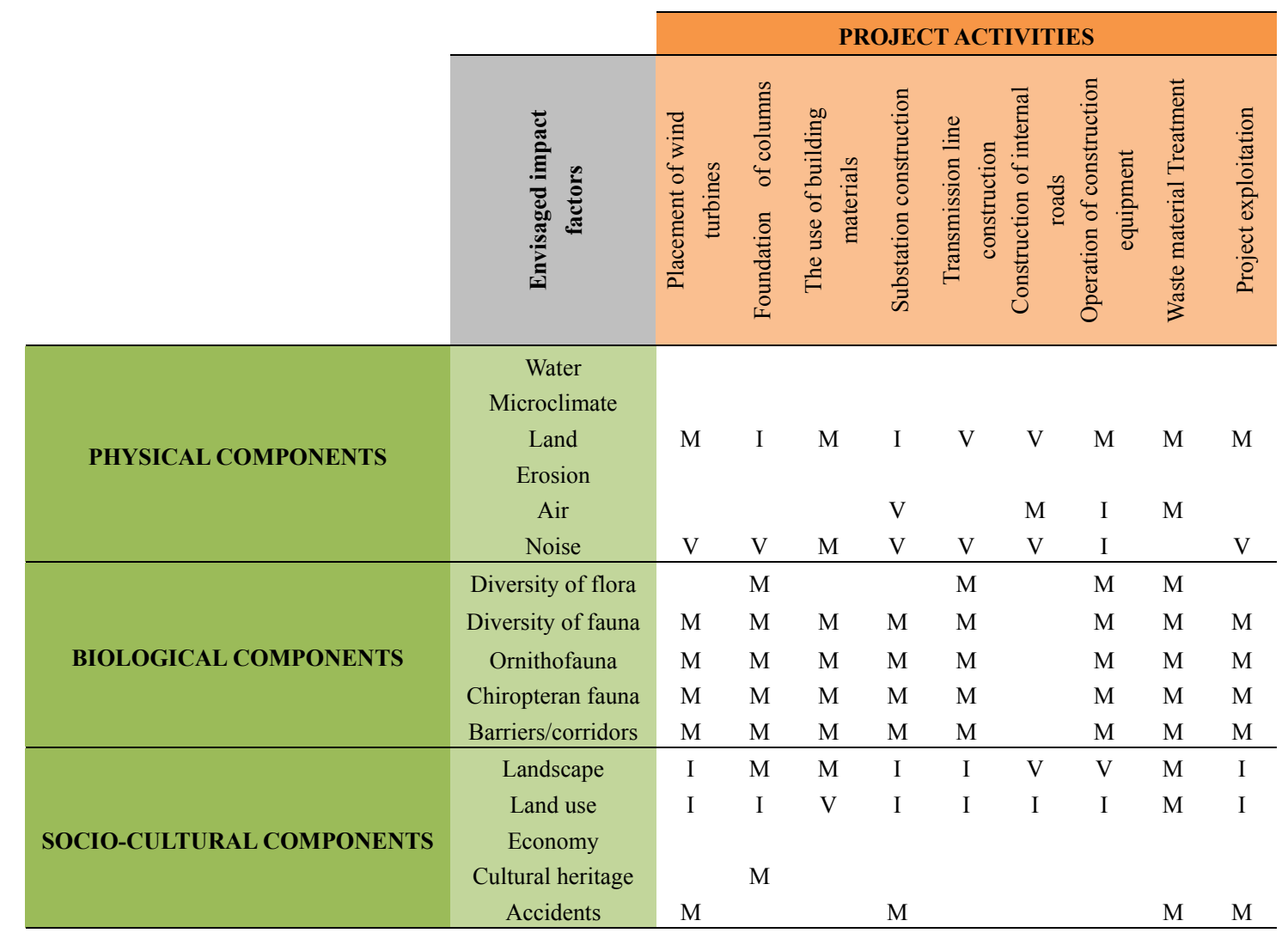


Table 4. Matrix of duration of the impact of factors on environmental components for WF, "Kladovo"

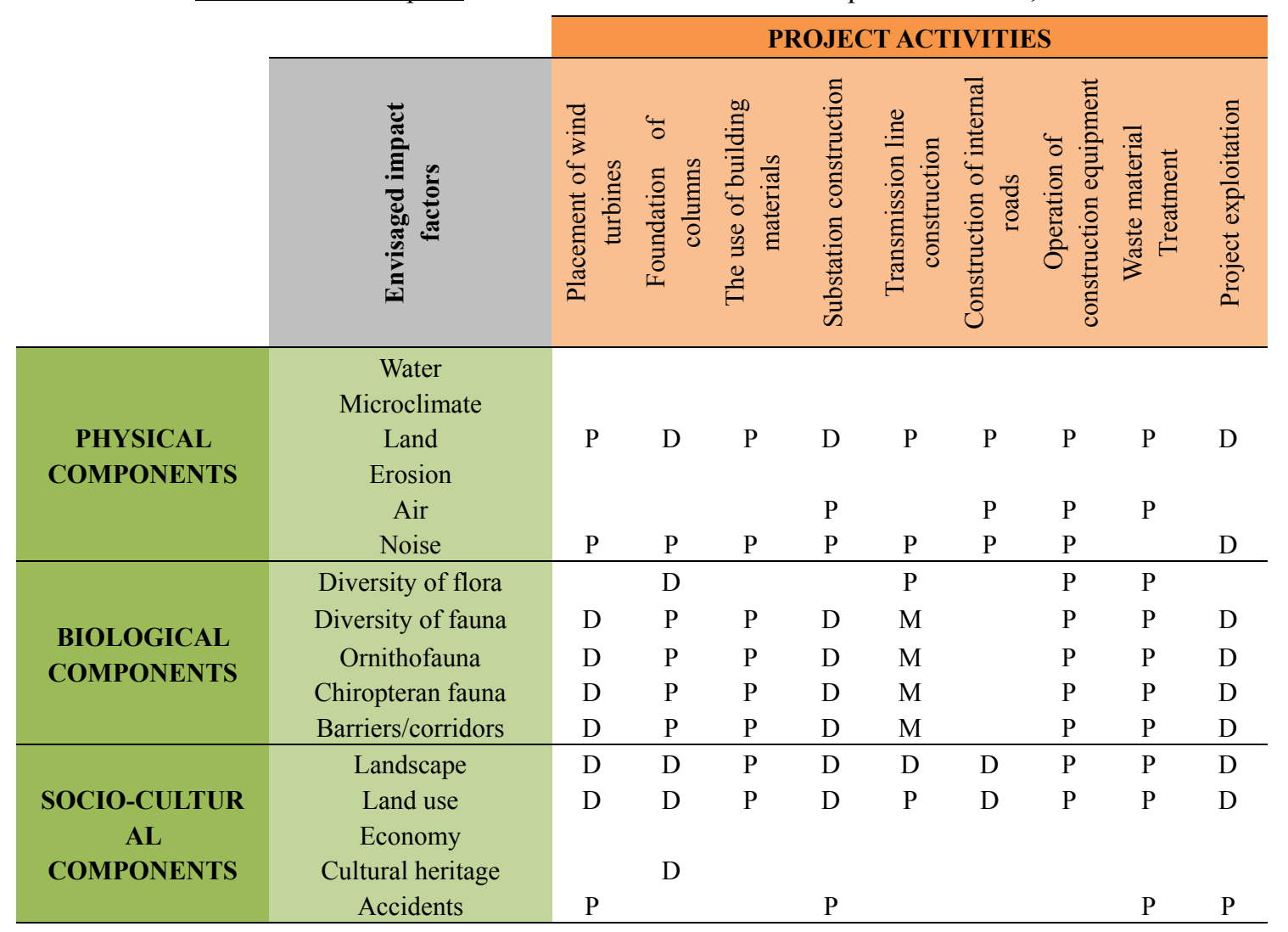

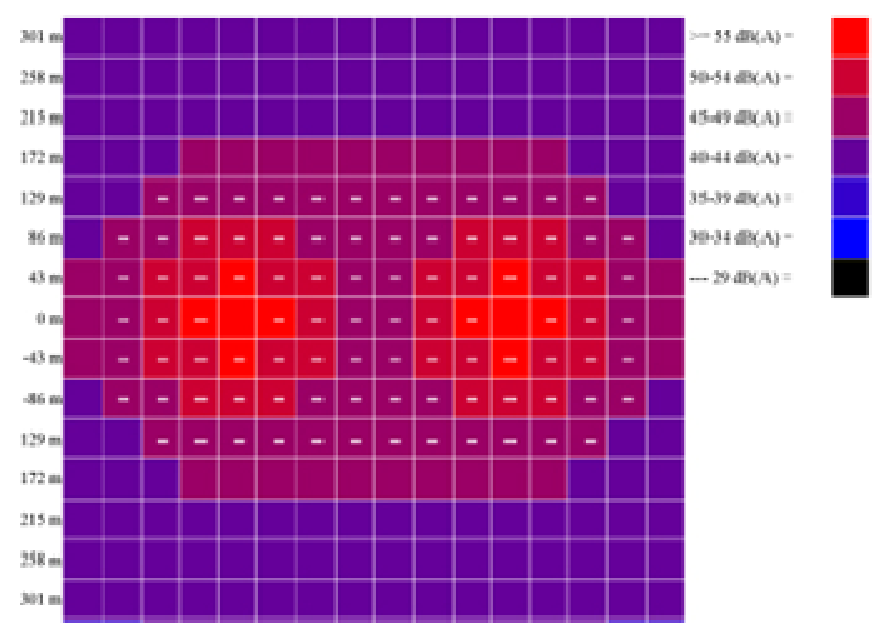

Figure 2. Spatial dispersion of wind turbine noise levels (Source: Danish Wind Industry Associoation)

Considering that in determining the disposition of wind turbine columns, the aspect of possible impact of noise has primarily been taken into account. Based on the model shown in Figure 2, it was found that wind turbine noise levels were lower than legally prescribed noise levels. The total average value of magnitudes of expected impacts of the project on noise levels is within low effects (1.55).

\subsubsection{Biological Components}

Based on analyzed data on the presence, directions and heights at which different types of birds fly over the area, as well as on the basis of the disposition of wind turbines, it can be concluded that the greatest impact of the construction and operation of the "Kladovo" Wind Farm will be on the most numerous and most frequent species of birds, such as common buzzard (Buteo buteo), as well as common raven (Corvus corax), although their number is incomparably smaller than the number of common buzzards. Other target species of birds flying at 
critical heights were smaller in number, or the critical heights were mostly out of the coverage of the parts of research location in which installation of wind turbines is planned. The shown positions of wind turbines have been carefully chosen, considering that they should be at least $1,000 \mathrm{~m}$ far from the Important Bird Area, as well as from the bed and right bank of the Danube river for which it was assumed to be an important migration corridor. In the location, no significant negative impacts have been assessed. Numerosity of birds belonging to each identified species is relatively small, because of which there are no significant effects on them. On the other hand, it is also necessary to emphasize the assessment of possible positive impacts of the wind farm construction and operation, as well as the construction of accompanying infrastructure, on certain species of birds. The total average of magnitude of expected impacts of the subject project on ornithofauna is within low effects (1.33).

As for bats, during the construction phase of the project, due to works on infrastructure, a part of woody and bushy plants in the location and its immediate surrounding, where an insignificant part of these types of plants is found, will be removed. Removal of woody plants in these zones will lead to the loss of these shelters, but this will have a negligible effect on local and migratory population, because almost the whole fund of their recorded and potential shelters is outside the zone of this impact. For some of these species, there are no, or no significant, hunting territories during all phases of their life cycle. Removal of woody plants in the zone of forest fragments near the "Đalu mare" hunting ground, which is the hunting territory of at least some significance in the location itself, would lead to the loss of the function of shelters. This would have a low effect on local and migratory population of these species, because the greatest part of their hunting territories is outside the wind farm location. However, after making suggestions to the investor on the importance of this forest fragment for chiropteran fauna found in the location, the disposition of wind turbines has been changed, thus the total risk of losing the hunting territory in the location is negligible. The total average of magnitude of expected impacts of the subject project on chiropteran fauna is within low effects (1.33).

Positioning and operation of wind turbines or other infrastructure in important flight corridors, or their immediate surroundings, would lead to the creation of barriers to normal daily transit activities of bats. Given that such activities of these or other species have not been recorded in the location, it can be concluded that the risk of losing flight corridors, if any, is negligible. Important migratory corridors of these species have not been recorded in the location. The total average of magnitude of expected impacts of the subject project on the creation of barriers/corridors is within low effects (1.11).

\subsubsection{Socio-Cultural Components}

The total average impact factor for these components falls into the category of low effects. The reason for this is because the location is isolated. The most important average value of impact factor is associated with general appearance of the landscape. Continual landscape transformation, as well as the complexity of landscape functions implies difficulties in meeting the obligations set out by documents at international and national levels (Maksin \& Milijić, 2010). Visual effects on its surroundings are actually an subjective impression which, besides observer's perception, can also depend on the type of landscape and its specific visual characteristics. Analyzing the subject location, it has been concluded that wind turbines will dominate the surrounding, so that the landscape will be only partially changed by the construction of the planned wind farm. It has also been concluded that the planned disposition of wind turbines, although originally based on wind source assessment, will not disturb the landscape characteristics, but will create a specific visual identity. On the other hand, the exposure/visibility of the location is small considering the distance from the nearest buildings and road infrastructure, thus diminishing the importance of potential impacts of the planned wind farm on landscape and ambience values of a wider space. The total average of magnitude of expected impacts of the subject project on the landscape is within low effects (1.66).

Taking into account the terrain configuration, disposition of wind turbines and existing buildings in the surrounding of the planned location, as well as the sun trajectory, it can be concluded that the planned wind turbines will not cast shadows on neighboring properties.

Physically, wind turbines occupy only several percents of the land covered by the wind farm, while the rest of the land between turbine foundations and around internal roads can be used for other purposes, i.e. for original purposes without any limitations. In this case, the area can be further used for agricultural production. Therefore, there are no significant impacts in terms of land-use change. The total average of magnitude of expected impacts of the subject project on land use is within low effects (1.22).

Although there are no registered protected archaeological sites, neither there are other elements of cultural heritage in the space covered by the subject project, it is still possible to come across undiscovered archeological remains during excavations for wind farm foundations. In such situation, it would be necessary to undertake 
adequate measures in order to preserve the remains, or to stop the works and inform the Cultural Heritage Preservation Institute. The total average of magnitude of expected impacts of the subject project on cultural heritage is within theoretical possibility $(0.22)$.

The risk of wind turbine accidents is very small. In the subject location, there is no immediate danger for the population even in case of serious damage. There are no residential settlements and roads in the surrounding area, thereby no any danger of wind turbine related accidents. In order to avoid possible accidental situations, it is also necessary to define within impact assessment the adequate protection measures and measures to reduce accident risks. The total average of magnitude of expected impacts of the subject project on the possibility of implying the accidental situations is within low effects (0.77) of local character.

\subsection{Effects of Cumulative Impact Factors on Environmental Components}

In Table 1, the activities in the phase of wind farm construction (operation of construction equipment and waste material treatment, installation of wind turbines and construction of foundations and substation), as well as possible impacts during the period of exploitation when possible impacts on ornithofauna and chiropteran fauna and increase in noise levels close to sound source can occur, are emphasized as factors having the greatest cumulative impact on environmental components.

The biological components are the most vulnerable primarily because of possible impacts on flying fauna. However, their effects range low. They are actually effects of low intensity only in the boundary area and mainly with limited time duration. The average assessment of effects of cumulative impact factors on environmental components is 0.82 . This impact factor value is within low effects.

Nevertheless, if negative effects of these and others factors are considered as a whole, then it should be pointed out that qualitative and quantitative losses in living fauna will still be negligible and, practically, spatially and time limited only to the location itself. The survival of any of species of important, vulnerable or rare ecosystems, or other natural values, will not be called into question.

\section{Discussion and Conclusions}

Taking into account the problems in the realization of the wind farm project in Serbia that are caused by the resistance of a part of stakeholders resulting from the fear of negative effects on the environment, the idea of the research was to supplement the current methodology used in EIA. It has been decided to carry out an EIA because it presents an instrument for environmental protection which is, according to the Serbian legislation, the most transparent to stakeholders since they are involved in all phases of the elaboration of this document. Thus, an opportunity has been created for presenting to the public the extent and significance of possible negative impacts on space and environment in a simple and unambiguous way, as well as for overcoming the existing problems through discussions.

The initial assumption in the research was that the realization of the planned wind farm project implies the use of renewable energy, the wind energy, by using clean technology for its exploitation so that significant adverse impacts to the environment are not to be expected, as well as that the resistance of a part of stakeholders has resulted from the fear of the unknown because no wind farm in Serbia has been realized that could prove or disapprove the existing assumptions.

A special attention in carrying out EIA for the "Kladovo" Wind Farm has been dedicated to the analysis of the state of the environment of the location planned for the construction of the "Kladovo" Wind Farm and its wider surrounding. By their nature, wind farms can imply certain adverse impacts on the environment, both in the phase of construction (impacts of temporary character) and in the phase of its exploitation. Possible dominant negative effects have been related to the flying fauna, i.e. ornithofauna and chiropteran fauna. In this context, within the analysis of the state of the environment, monitoring of ornithofauna and chiropteran fauna was carried out in the period between March 2011 and February 2012 for the needs of undertaking the preventive measures for the protection of flying fauna. Based on observations, the final spatial disposition of wind turbines has been determined, i.e. certain wind turbine columns have been relocated to locations in which the possibility of jeopardizing the flying fauna has been minimized (preventive measures for the protection of flying fauna), while the results of observations have been incorporated into EIA and presented to the public in the earliest stage of EIA.

After the analysis of the state of the environment, as well as the analysis of project documentation, a multi-criteria evaluation of possible impacts of the "Kladovo" WF on environmental components using the Leopold matrix has been carried out. For the needs of the evaluation, 9 possible factors resulting from planned project activities have been singled out from the list of potential impact factors (jeopardizing factors) which 
could be expected for such type of interventions in nature. Impact factors have been evaluated for each environmental component relevant for EIA, as well as in relation to the impact magnitude. Furthermore, physical, biological and socio-cultural characteristics of the environment in the subject location have been separated, and the total of 16 environmental components defined within them.

All the above mentioned is the standard procedure in using the Leopold matrix which is a procedure for quantitative expert evaluation of planned activities related to the magnitude (intensity) of impact. However, by applying such approach, the spatial dispersion of identified impacts, probability of identified impacts actually occurring and, finally, the duration of identified impacts, still remains unclear. In this context, the idea was to additionally build the additional aspects into the Leopold matrix in form of a group of criteria that would be used in additional evolution of the planned project activities, assuming that the presentation and elaboration of obtained results would give to the public a complete picture of real impacts that could be expected in the realization of the "Kladovo" Wind Farm project. In this context, the following three additional criteria have been derived for: significance (spatial dispersion), probability and duration of impact, with the total of ten additional criteria. The evaluation of planned activities has been carried out for each group of criteria using the Leopold matrix. In addition to tabular presentation, the (positive and negative) results have also been elaborated in detail both for each factor and cumulatively in relation to environmental components.

The presented results that have been obtained using multicriteria analysis and evaluation have been surprisingly well received in the procedure of discussion and public insight in EIA for the "Kladovo" Wind Farm. The reason lies in the fact that adverse reaction of a part of the public has changed when it has been proven that certain identified negative effects will be micro-localized and that they will be only of a temporary character, as well as that they will occur only in a short period of time, which is, for example, the case with possible pollution during the wind farm construction. Or, when it has been shown that increased levels of noise caused by the rotation of wind turbine blades will be dominant only near the sound source, as well as that spatial dispersion of noise levels will exclude the possibility of exposure to higher levels of noise of the people living in the closest residential buildings considering their distance from the wind farm.

It can be concluded that the applied approach has yielded good results in overcoming the problems in the realization of the "Kladovo" Wind Farm project and that it is also possible to successfully use this approach for other similar projects in the field of implementation of renewable energy (RE) sources. In addition, the use of multicriteria analysis and evaluation provide to decison makers the possibility of considering possible effects of the project on the environment, as well as make the decision-making regarding the choise of optimal solutions a lot more simple. This is particularly important for Serbia because this will enable easier realization/implementation of renewable energy projects from the aspect of environmental conservation.

Future research directions for the EIA method, as well as for its development, could be also reflected in highlighting the positive implications of projects in the field of implementation of renewable energy (RE) sources, actually that the multi-criteria evaluation should not be based only on the identification and dominant presentation of negative effects of a planned project, but also on a balanced presentation of both the positive and negative effects, in this way bringing greater objectivity to the process of impact assessment. In this process, a special attention is to be dedicated to the use of: GIS tools; AHP and similar mathematical methods and models in the process of environmental impact assessment in order to minimize subjectivity in this process, as well as in the decision-making process.

\section{Acknowledgments}

This paper has resulted from the research conducted within the scientific projects "Spatial, ecological, energy, and social aspects of settlement development and climate change - their mutual impacts", TR 36035; "Sustinable spatial development of Danubian Serbia", TR36016; and "The role and implementation of the national spatial plan and regional development documents in renewal of strategic research, thinking and governance in Serbia", III47014, all financed by the Ministry of Education, Science and Technological Development of the Republic of Serbia in the period 2011-2014.

\section{References}

Bhatnagar, K. C. (2009). Environmental management - New Directions for the $21^{\text {st }}$ Century, New Delhi: Global India Publications Pvt Ltd.

Chatterjee, N. C., \& Bose, G. K. (2013). Selection of vendors for wind farm under fuzzy MCDM environment.

Crnčević, T., Marić, I., \& Josimović, B. (2011). Strategic Environmental Assessment and Climate Change in the Republic of Serbia - Support to the Development and Adjustment Process, SPATIUM. No 26, 14-19. 
Decree on the Ecological Network ("Official Gazette of the Republic of Serbia”, No. 102/10)

Energy Sector Development Strategy of the Republic of Serbia until 2015 ("Official Gazette of the Republic of Serbia", No. 44/05)

Ismail, W. K. W., Abdullah, L., Zhang, J., \& Zhang, W. (2012). A new Environmental Performance Index using analytic hierarchy process: a case of ASEAN countries.

Josimović, B., \& Pucar, M. (2010). The strategic environmental impact assessment of electric wind energy plants:

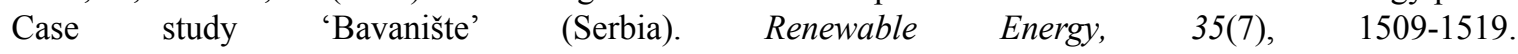
http://dx.doi.org/10.1016/j.renene.2009.12.005

Leopold, L. B., Clarke, F. E., Hanshaw, B. B., \& Balsley, J. R. (1971). A Procedure for Evaluating Environmental Impact in Geological Survey Circular 645, USGS, Washington DC.

Maksin, M., \& Milijić, S. (2010). Strategic planning for sustainable spatial, landscape and tourism development in Serbia, SPATIUM. No 23, 30-37

Radej, B. (2011). Synthesis in policy impact assessment. Evaluation, 17(2), 133-150.

Regulation on the Methodology for Determining the Acoustic Zone ("Official Gazette of RS", No. 72/10)

\section{Copyrights}

Copyright for this article is retained by the author(s), with first publication rights granted to the journal.

This is an open-access article distributed under the terms and conditions of the Creative Commons Attribution license (http://creativecommons.org/licenses/by/3.0/). 